\title{
First commissioning of the SuperKEKB vacuum system
}

\author{
Y. Suetsugu, K. Shibata, T. Ishibashi, K. Kanazawa, M. Shirai, S. Terui, and H. Hisamatsu \\ High Energy Accelerator Research Organization (KEK), Tsukuba 305-0801, Japan
}

(Received 27 September 2016; published 16 December 2016)

\begin{abstract}
The first (Phase-1) commissioning of SuperKEKB, an asymmetric-energy electron-positron collider at KEK, began in February 2016, after more than five years of upgradation work on KEKB and successfully ended in June 2016. A major task of the Phase-1 commissioning was the vacuum scrubbing of new beam pipes in anticipation of a sufficiently long beam lifetime and low background noise in the next commissioning, prior to which a new particle detector will be installed. The pressure rise per unit beam current decreased steadily with increasing beam dose, as expected. Another important task was to check the stabilities of various new vacuum components at high beam currents of approximately $1 \mathrm{~A}$. The temperature increases of the bellows chambers, gate valves, connection flanges, and so on were less than several degrees at $1 \mathrm{~A}$, and no serious problems were found. The effectiveness of the antechambers and TiN coating in suppressing the electron-cloud effect (ECE) in the positron ring was also confirmed. However, the ECE in the Al-alloy bellows chambers was observed where TiN had not been coated. The use of permanent magnets to create an axial magnetic field of approximately $100 \mathrm{G}$ successfully suppressed this effect. Pressure bursts accompanying beam losses were also frequently observed in the positron ring. This phenomenon is still under investigation, but it is likely caused by collisions between the circulating beams and dust particles, especially in the dipole magnet beam pipes.
\end{abstract}

DOI: 10.1103/PhysRevAccelBeams.19.121001

\section{INTRODUCTION}

SuperKEKB is an asymmetric-energy electron-positron collider at KEK, Japan, and is a successor to the former KEKB (KEKB B-factory) [1-4]. SuperKEKB consists of an injector, a positron damping ring, a main ring (MR), and the Belle II particle detector (Fig. 1). The MR is composed of two rings, each with a circumference of $3016 \mathrm{~m}$. The high energy ring (HER) and low energy ring (LER) are for 7.0 GeV electrons and $4.0 \mathrm{GeV}$ positrons, respectively. Table I lists the key MR design parameters that are relevant to the vacuum system. The designed beam currents are 2.6 and 3.6 A for the HER and LER, respectively, and the maximum bunch number of both of rings is 2500 . The beams have very low emittances $(8.6-11.5 \mathrm{pm}$ in the vertical direction), and the vertical beam sizes at the collision point are reduced to approximately $50-60 \mathrm{~nm}$. The designed luminosity is $8 \times 10^{35} \mathrm{~cm}^{-2} \mathrm{~s}^{-1}$, which is approximately 40 times that achieved in KEKB [4].

The upgradation of the MR vacuum system, as one of the key components of SuperKEKB, began in 2010 [5,6]. Approximately $93 \%$ of the beam pipes and vacuum components of the LER were replaced with new ones. On the other hand, approximately $80 \%$ of the components in the HER were reused because the layout of the magnets did not

Published by the American Physical Society under the terms of the Creative Commons Attribution 3.0 License. Further distribution of this work must maintain attribution to the author(s) and the published article's title, journal citation, and DOI. change significantly. Note that the components of HER were left undisturbed in the tunnel during the upgradation work keeping vacuum inside although all vacuum pumps were turned off. However, these components were sometimes exposed to air temporarily when broken bellows chambers or ion pumps were replaced with new ones [5].

The MR vacuum system was newly designed based on various experiences with the KEKB vacuum system, and leading-edge concepts were introduced [5-8]. Beam pipes with antechambers were adopted to reduce the beam

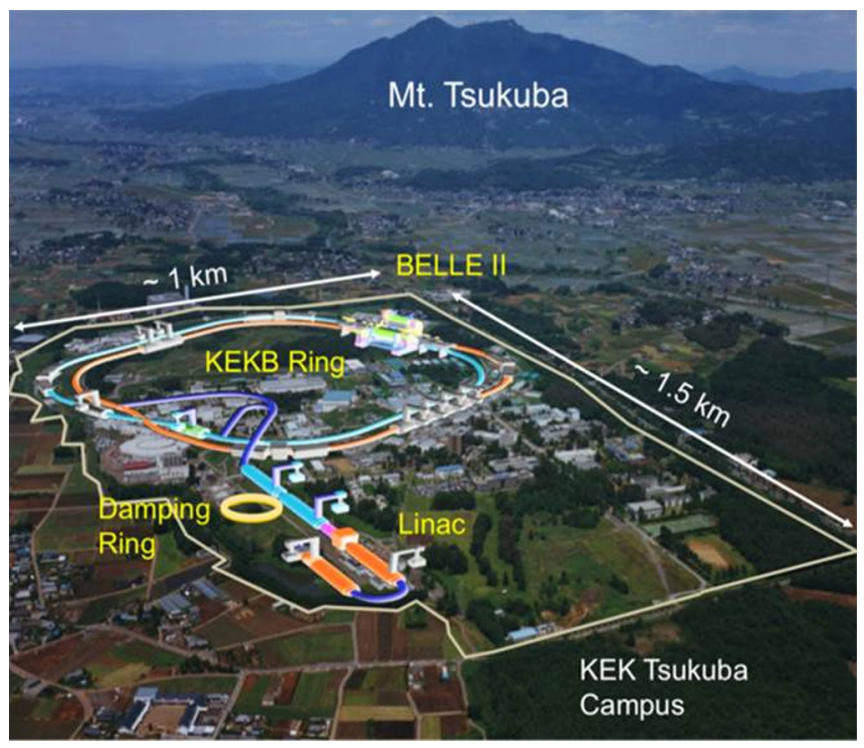

FIG. 1. Layout of SuperKEKB at the KEK Tsukuba campus. 
TABLE I. Main design parameters of the SuperKEKB MR.

\begin{tabular}{|c|c|c|c|}
\hline & LER & HER & Units \\
\hline Beam energy & 4.0 & 7.0 & $\mathrm{GeV}$ \\
\hline Beam current & 3.6 & 2.6 & A \\
\hline Circumference & \multicolumn{2}{|c|}{3016} & $\mathrm{~m}$ \\
\hline Bunch numbers & \multicolumn{2}{|c|}{2500} & \\
\hline Bunch length & 6.0 & 5.0 & $\mathrm{Mm}$ \\
\hline$\varepsilon_{x} / \varepsilon_{y}$ & $3.2 / 8.64$ & $4.6 / 11.5$ & $\mathrm{~nm} / \mathrm{pm}$ \\
\hline$\beta_{x} / \beta_{y}$ (at collision point) & $32 / 0.27$ & $25 / 0.3$ & $\mathrm{~mm}$ \\
\hline Luminosity & \multicolumn{2}{|c|}{$8 \times 10^{35}$} & $\mathrm{~cm}^{-1} \mathrm{~s}^{-1}$ \\
\hline \multicolumn{4}{|l|}{$\begin{array}{l}\text { SR parameters in arc } \\
\text { (design current) }\end{array}$} \\
\hline Total power & 1.1 & 5.3 & MW \\
\hline Critical energy & 1.9 & 7.3 & $\mathrm{keV}$ \\
\hline $\begin{array}{l}\text { Average photon } \\
\text { density }\end{array}$ & $5.3 \times 10^{18}$ & $6.7 \times 10^{18}$ & photons $\mathrm{s}^{-1} \mathrm{~m}^{-1}$ \\
\hline
\end{tabular}

impedance and to relax the irradiation power density of the synchrotron radiation (SR) [9-11]. The antechambers also effectively suppress the electron-cloud effect (ECE) [1113], which had been a serious problem in the positron ring [14-18]. In the arc sections of the LER, for reference, the typical beam-channel diameter was $90 \mathrm{~mm}$, the total width including antechambers was $220 \mathrm{~mm}$ (i.e., the depth of each antechamber was $65 \mathrm{~mm}$ ), and the height of each antechamber was $14 \mathrm{~mm}$. Approximately 1230 new beam pipes with various lengths were fabricated. As a radiofrequency (rf) shielding structure in the bellows chambers and gate valves, a comb-type rf shield was developed and adopted on a large scale for the first time $[19,20]$. Approximately 1240 bellows chambers and 40 gate valves were installed in the LER and HER. Matsumoto-Ohtsuka (MO)-type flanges, which can provide small steps at the connection part inside and accommodate the cross sections of the antechambers, were also adopted on a large scale for the first time [21,22]. Approximately 5000 flanges were installed in the new beam pipes and bellows chambers. Nonevaporable getter (NEG) strips (St707, SAES Getters Co. Ltd.) were used as a main pump. They were installed in one of the antechambers and generate a uniformly distributed pumping system along the beam pipes at arc sections $[23,24]$. To counteract the ECE in the LER, antechamber structures were adopted as described above to suppress the effects of photoelectrons [11-13]. A TiN film was coated onto most of the new Al-alloy and $\mathrm{Cu}$ beam pipes, since it can effectively reduce the secondary electron yield (SEY), that is, the multipacting of electrons [25-29]. Furthermore, longitudinal grooves and clearing electrodes were prepared in the dipole magnets and wiggler magnets, respectively [29-34]. Axial magnetic fields (solenoidal magnetic fields) will be applied along the beam pipes in the drift spaces in the future [35-37], but these were not prepared for the first (Phase-1) commissioning.

The upgradation of the vacuum system had almost been completed by the end of 2015 [38]. Figure 2 shows the

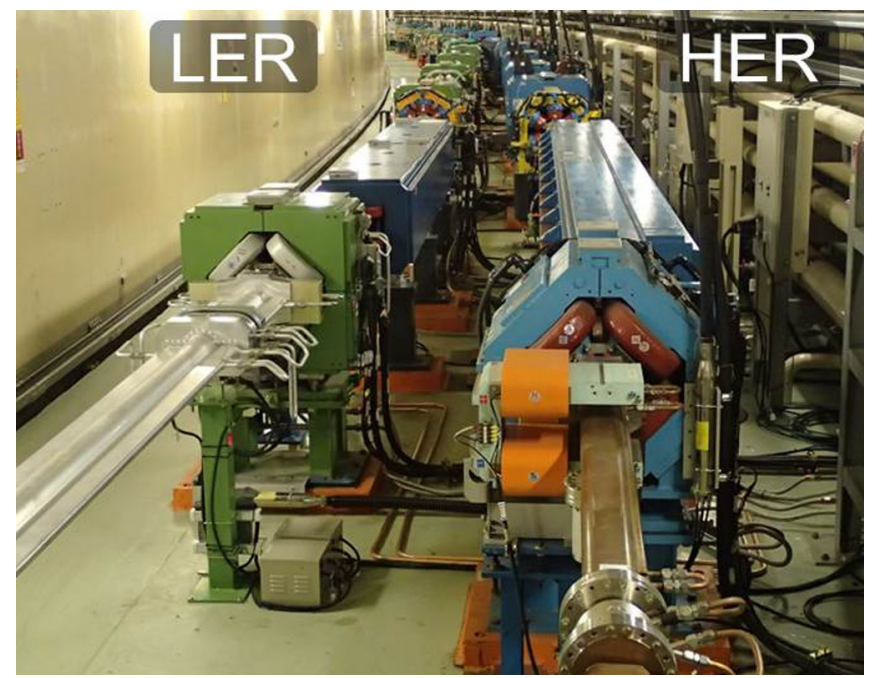

FIG. 2. Present view of the SuperKEKB tunnel.

current configuration of the beam pipes and magnets in an arc section of the MR tunnel. After the final tuning of the complete system, the Phase-1 commissioning started in February 2016 and ended in June [1]. In the Phase-1 commissioning, which was dedicated to accelerator tuning, no particle detector for high energy physics was installed. The Phase- 1 commissioning had three main tasks: the first was vacuum scrubbing in anticipation of a sufficiently long beam lifetime and background-noise reduction for the particle detector in the next (Phase-2) commissioning planned for 2017, the second was the starting of various components in the ring and checks of stability and effectiveness of these components at high beam currents around $1 \mathrm{~A}$ and the third was the establishment of beamoperation tools such as those for beam optics and closedorbit distortion corrections.

In the following, observations of the primary MR vacuum system obtained during the Phase-1 commissioning, including the vacuum scrubbing status, temperature rises of the main vacuum components, and effectiveness of ECE countermeasures, are presented. Subsequently, two major problems experienced during the commissioning, that is, the ECE in the Al-alloy bellows chambers and the frequent pressure bursts accompanying beam losses in the LER, are reported.

\section{MAIN RESULTS}

\section{A. Operation summary}

The beam injection into the LER and HER started on February 8 and 22, respectively, in 2016 [1]. The beams were successfully stored after several days of tuning in both cases. The vacuum system worked well and experienced no serious problems during the Phase-1 commissioning [38].

For the LER and HER, Figs. 3(a) and 3(b), respectively, present the histories of the average pressure in the whole 


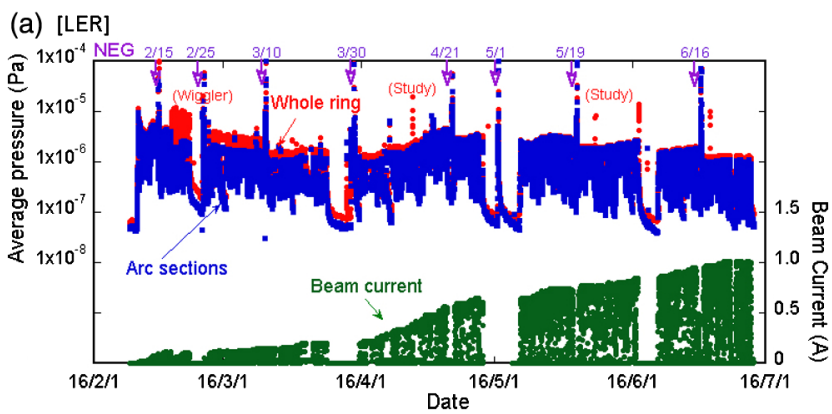

(b) $[\mathrm{HER}]$

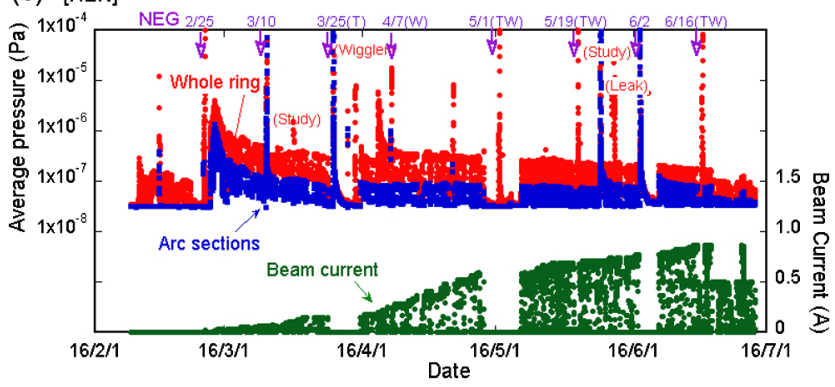

FIG. 3. Histories of the average pressure in the whole ring (red circles), average pressure in the arc sections (blue squares), and stored beam currents for (a) the LER and (b) the HER. Arrows indicate the NEG conditioning times; here, "T" and "W" mean that the NEG was conditioned only at the "Tsukuba straight section" and "Wiggler sections," respectively.

ring (red circles), including in the straight sections (such as the wiggler sections, beam injection sections, and accelerating cavity sections), the average pressure in only the arc sections (blue squares), and the stored beam current from February to June. Until the end of June, the integrated beam currents (i.e., the beam doses) were 780 and $660 \mathrm{Ah}$, and the maximum stored beam currents were 1.01 and $0.87 \mathrm{~A}$ for the LER and HER, respectively. It should be noted that high beam currents of approximately 1 A were achieved in less than five months. For most of the operation, the bunch fill pattern consisted of a single train of 1576 bunches with a spacing of approximately $6 \mathrm{~ns}$ (hereafter, this fill pattern is denoted as $1 / 1576 / 6 n)$. For the whole LER, the base pressure $\left(P_{\text {base }}\right)$ and average pressure at the maximum beam current $\left(P_{\max }\right)$ were measured to be $5 \times 10^{-8}$ and $1 \times 10^{-6} \mathrm{~Pa}$, respectively. The $P_{\max }$ of the whole ring and that of the arc sections, where most of the beam pipes were newly fabricated, were found to be almost the same. The beam lifetime at the maximum beam current was approximately $70 \mathrm{~min}$ when using an emittance control knob (ECK). The ECK intentionally increases the beam emittances by adjusting sextuple magnets and relaxes the Touschek lifetime effect. On the other hand, $P_{\text {base }}$ and $P_{\max }$ of the whole HER were found to be $3 \times 10^{-8}$ and $2 \times 10^{-7} \mathrm{~Pa}$, respectively. Note that $P_{\max }$ was measured to be $6 \times 10^{-8} \mathrm{~Pa}$ in the arc sections, where most beam pipes were reused from KEKB (see the next section). The beam lifetime at the maximum beam current was approximately $400 \mathrm{~min}$. The arrows and dates at the tops of Figs. 3(a) and 3(b) indicate the NEG conditioning times. Note that the pressures presented here and hereafter are 3 times the values displayed by the vacuum gauges, taking into account the conductance between the beam channels, where the circulating beams pass, and the vacuum gauge ports located above the sputter ion pumps [7].

\section{B. Vacuum scrubbing}

Figures 4(a) and 4(b) present the average pressures normalized by a unit beam current [i.e., the pressure rise $\left.d P / d I\left(\mathrm{~Pa} \mathrm{~mA}^{-1}\right)\right]$ for the LER and HER, respectively, as functions of the beam dose. In the calculation of $d P / d I$, the average pressure was used instead of the pressure increase (i.e., the difference between the average pressure and the
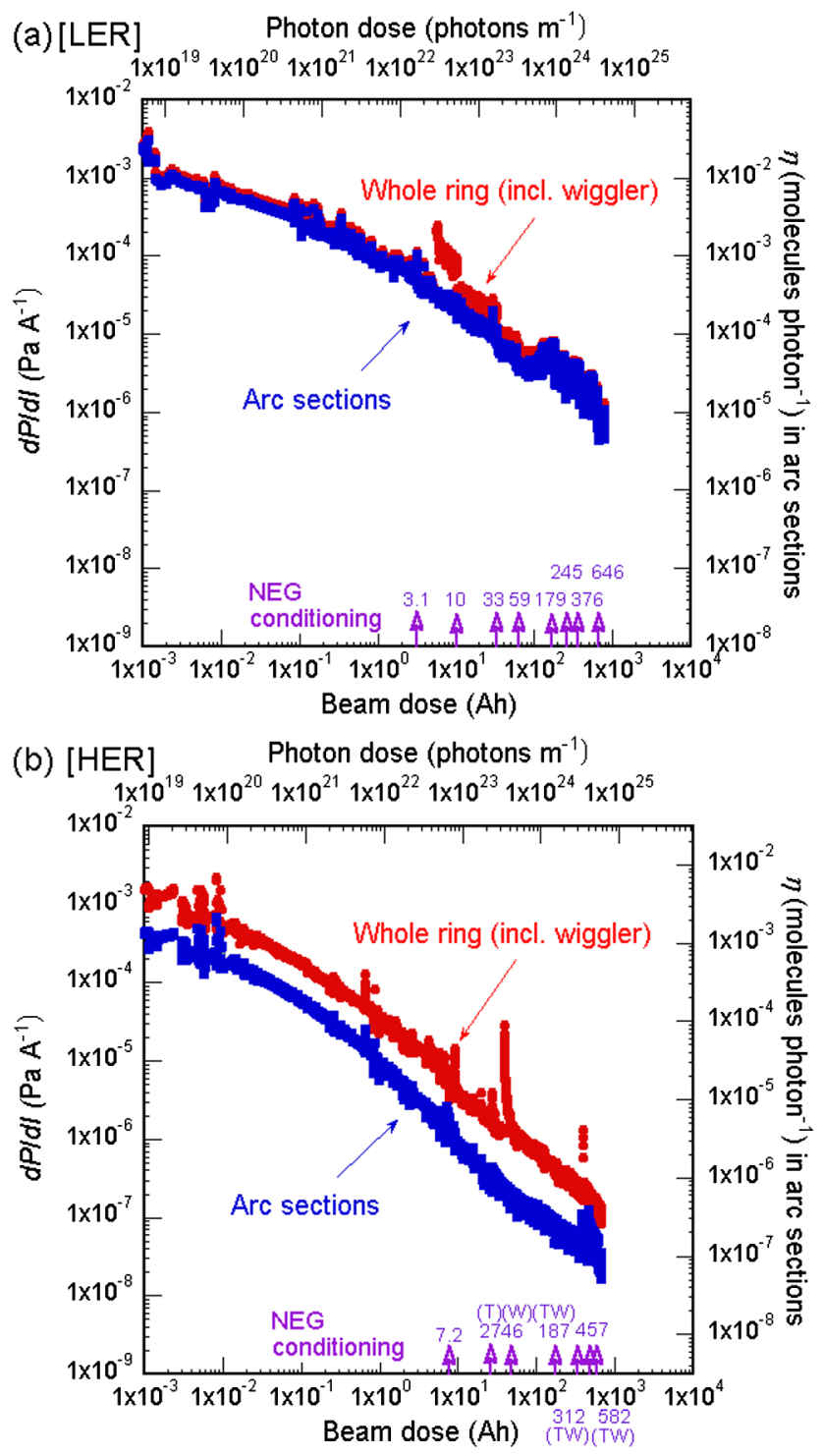

FIG. 4. $\quad d P / d I\left(\mathrm{~Pa} \mathrm{~A}^{-1}\right)$ and $\eta$ (molecules photon $\left.{ }^{-1}\right)$ in the arc sections as functions of the beam dose (Ah) and $D$ (photons $\mathrm{m}^{-1}$ ) in the arc sections for (a) the LER and (b) the HER. 
base pressure) for simplicity and convenience. The base pressure gradually changes with time and is sensitive to the temperature of beam pipes. Therefore, to minimize the influence of the base pressure in the calculation, the average pressures used in the calculation were the values observed when the beam currents were greater than $60 \%$ of the maximum beam currents at that time $\left(I_{\max }\right)$. The circles (red) and squares (blue) correspond to the $d P / d I$ of the whole ring and of only the arc sections, respectively. The total pressures were measured with approximately 300 cold cathode gauges (CCG, Model C-5, DIAVAC Ltd Japan) in each ring at pump ports located every $10 \mathrm{~m}$ on average. The average pressures in the arc sections were calculated using approximately 100 CCGs. Again, the arrows indicate the NEG conditioning times. In each graph, the upper axis represents the photon dose [i.e., the integrated numbers of photons per unit length (photons $\mathrm{m}^{-1}$ )] in the arc sections, and the right axis indicates the photon stimulated desorption (PSD) rate $\eta$ (molecules photon ${ }^{-1}$ ) in the arc section, evaluated by assuming linear pumping speeds of 0.06 and $0.03 \mathrm{~m}^{3} \mathrm{~s}^{-1} \mathrm{~m}^{-1}$ for the LER and HER, respectively, and by considering the saturation of NEG pumping speed [24]. The stepwise patterns at the NEG conditioning timings shown in Figs. 3(a) and 4(a) indicate the saturation of NEG pumping speeds.

For the LER, $d P / d I$ steadily decreases with increasing beam dose, as shown in Fig. 4(a). In the arc sections, the beam pipes of all of which were newly fabricated, $d P / d I$ is approximately $8 \times 10^{-7} \mathrm{~Pa}^{-1}$ at a beam dose of $780 \mathrm{Ah} . \eta$ is approximately $7 \times 10^{-6}$ molecules photon $^{-1}$ at

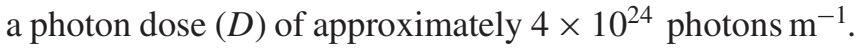
The beam pipes were constructed from an Al alloy, and their inner surfaces were coated with TiN to counteract the ECE as described In Sec. I [27]. During the initial stage $\left(D \sim 10^{19}\right.$ moleculesphoton $\left.^{-1}\right), \quad \eta$ $\left(1 \times 10^{-2}\right.$ moleculesphoton $\left.^{-1}\right)$ is several times lower than its value in KEKB $\left(4 \times 10^{-2}\right.$ molecules photon $\left.^{-1}\right)$, in which circular $\mathrm{Cu}$ beam pipes without any coating were used [7]. At $D=4 \times 10^{24}$ photons $\mathrm{m}^{-1}$, however, $\eta$ $\left(7 \times 10^{-6}\right.$ molecules photon $\left.^{-1}\right)$ has almost the value as in KEKB at the same photon dose. $\eta$ decreases with $D$ as $\eta \propto D^{-0.5}$ and $\eta \propto D^{-0.8}$ at $D$ values of approximately $1 \times 10^{22}$ and $1 \times 10^{24}$ photons $\mathrm{m}^{-1}$, respectively. The slope $\eta$ gradually increases with increasing $D$. Note that $\eta$ slightly increased when $\mathrm{D}>6 \times 10^{23}$ photons $\mathrm{m}^{-1}$, as shown in Fig. 4(a). The main cause of this increase was the nonlinear pressure increase with increasing beam current due to the gas desorption from electron multipacting in the Al-alloy bellows chambers without TiN coating, as described in Sec. III A. Therefore, the $\eta$ values in this region do not reflect the real PSD rate.

$d P / d I$ for HER also decreases steadily with increasing beam dose, as shown in Fig. 4(b). In the arc sections, $d P / d I$ was approximately $4 \times 10^{-8} \mathrm{~Pa} \mathrm{~A}^{-1}$ at a beam dose of $660 \mathrm{Ah} . \eta$ is approximately $1 \times 10^{-7}$ molecules photon $^{-1}$ at $D=5 \times 10^{24}$ photons $\mathrm{m}^{-1}$, and decreases with $D$ as $\eta \propto D^{-0.8}$ from $D=1 \times 10^{22}$ photons $^{-1}$ to $D=1 \times$ $10^{24}$ photons $^{-1} \cdot \eta$ is lower and shows a steeper decrease in the early stage in the HER compared to that in the LER. Furthermore, $\eta$ decreases less rapidly at $D>1 \times$ $10^{24}$ photons $\mathrm{m}^{-1}$, but this change occurs because the effect of the base pressure is not negligible in the $d P / d I$ calculations described above.

It is interesting to note that $\eta$ in the HER is lower than that in the HER of KEKB from the beginning [7]. The $\eta$ at $D=5 \times 10^{24}$ photons $\mathrm{m}^{-1}\left(1 \times 10^{-7}\right.$ molecules photon $\left.^{-1}\right)$ is much lower than that in the case of KEKB $\left(2 \times 10^{-6}\right.$ molecules photon $\left.^{-1}\right)$ at the same $D$, and its value is almost the same as that in the final stage of KEKB [7]. Since most of the beam pipes in the arc sections of the HER were reused from KEKB, their surfaces "remember" the conditions in KEKB after sufficient vacuum scrubbing (memory effect), even though they were sometimes exposed to air for the vacuum work. Note that the critical energy in the HER $(7.3 \mathrm{keV})$ is actually lower than that in the HER of KEKB $(12 \mathrm{keV})$, but the large difference of $\eta$ cannot be solely explained by this difference in the critical energy.

During the commissioning, the residual gases were monitored using a quadrupole mass analyzer (QMA, MicroVision, MKS Instruments) in an arc section of the LER, in which new beam pipes were installed. The QMA was located just above a sputter ion pump. Figure 5(a) presents the ion current changes normalized by the beam current as functions of the beam dose for the primary residual gases, namely $\mathrm{H}_{2}(m / z=2), \mathrm{CO}(m / z=28)$, $\mathrm{CH}_{4}(m / z=16), \mathrm{H}_{2} \mathrm{O}(m / z=18)$, and $\mathrm{CO}_{2}(m / z=44)$ in order of decreasing abundance. The high partial pressure of methane should be due to the pumping system using NEG as a main pump, because NEG pumps do not absorb inert gases such as methane and argon. Because the beam pipes were not baked in the tunnel, water vapor remains in the beam pipe [39]. The stepwise pattern, which is also observable in the total pressure [Fig. 4(a)], represents the NEG conditioning timing. For reference, Fig. 5(b) shows the mass spectra before and after the activation of a NEG at a beam dose of approximately $180 \mathrm{Ah}$ and a beam current of $510 \mathrm{~mA}$.

\section{Status of the new vacuum components}

SuperKEKB is the first machine to adopt, on large scale, novel vacuum components developed in the KEKB era, such as stepless MO-type flanges and comb-type rf shields for the bellows chambers and gate valves. Another major task of the Phase-1 commissioning was to confirm the stability of these components. Overall, no overheating, discharging, or abnormal pressure increases were observed in these components during the commissioning. For example, the temperature rises in the MO-type connection 


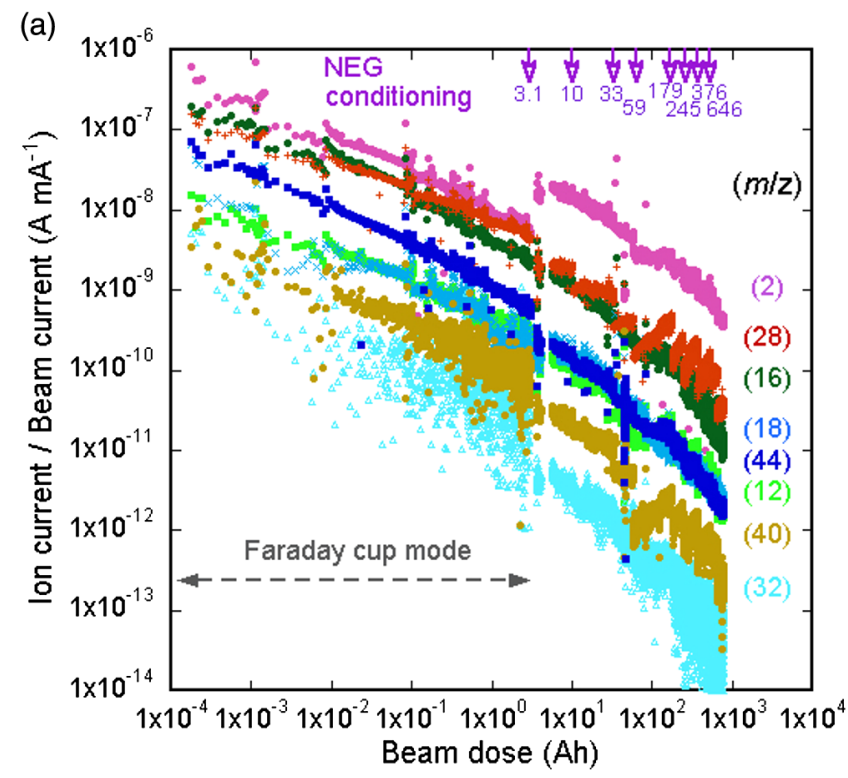

(b)

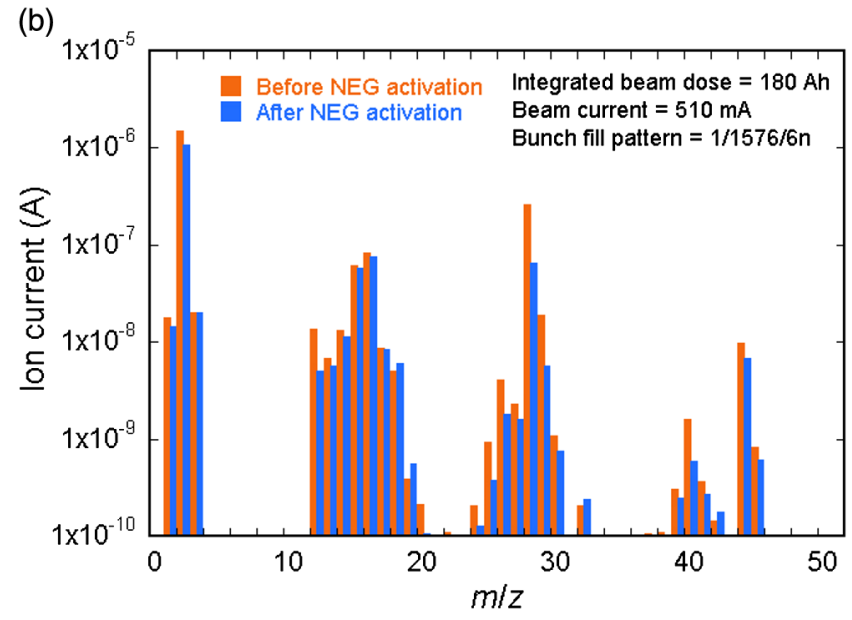

FIG. 5. (a) Ion currents for typical gases normalized by beam current $\left(\mathrm{A} \mathrm{mA} \mathrm{m}^{-1}\right)$ measured by a residual gas analyzer in an arc section of LER as functions of the beam dose (Ah). (b) Mass spectra before and after the activation of NEG at a beam dose of approximately $180 \mathrm{Ah}$ and a beam current of $510 \mathrm{~mA}$.

flanges (Al alloy) as functions of the beam current are presented in Fig. 6(a). The average temperature increase is less than $4^{\circ} \mathrm{C}$ in at $1 \mathrm{~A}(1 / 1576 / 6 n)$. No air leaks occurred in the connection flanges. Examples of the temperature increases in the bellows chambers are shown in Fig. 6(b). These bellows chambers were located near the beam collimators where the extra higher-order modes (HOMs) are easily excited [40-43]. The overheating of bellows chambers with conventional finger-type rf shields was frequently observed in KEKB [8]. In this case, however, the temperature increases are less than $2{ }^{\circ} \mathrm{C}$ as shown in Fig. 6(b), and are $1{ }^{\circ} \mathrm{C}$ at most for the bellows chambers at other locations. The temperature increases of the gate valves were also measured and found to be less than $2^{\circ} \mathrm{C}$.

The NEG pumps in the LER and HER were activated 8 and 7 times, as indicated in Figs. 3 and 4, respectively,
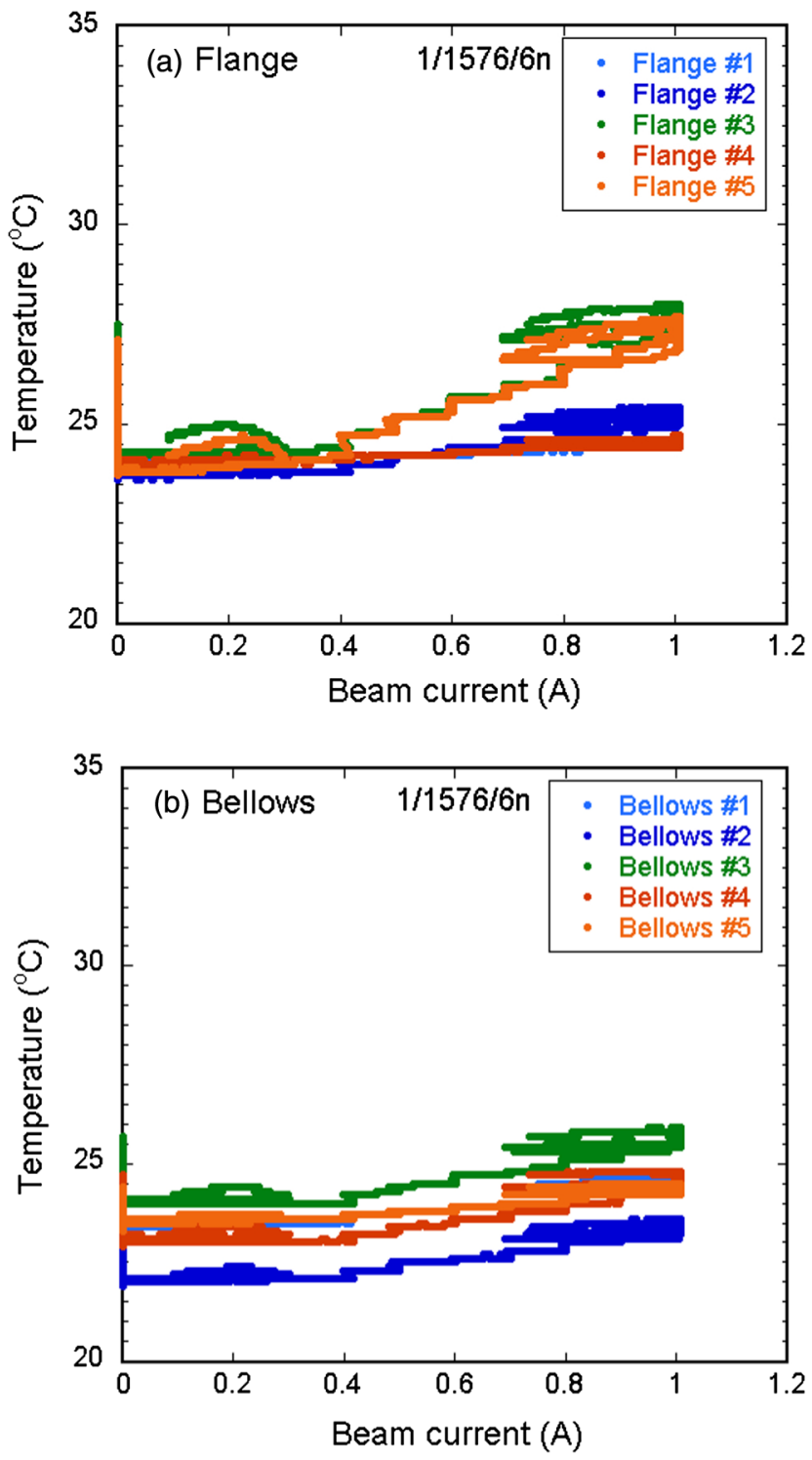

FIG. 6. Typical temperature changes $\left({ }^{\circ} \mathrm{C}\right)$ of (a) five MO-type flanges and (b) five bellows chambers near the beam collimators versus the beam current (A), where the bunch fill pattern was $1 / 1576 / 6 n$.

during the Phase-1 commissioning, which lasted for approximately five months. In the activation process, the NEG strips were heated up to approximately $400^{\circ} \mathrm{C}$ by sheath heaters [23]. The maximum temperatures on the outside surfaces of the antechambers were approximately $80^{\circ} \mathrm{C}$ and $28^{\circ} \mathrm{C}$ with and without water flowing in the cooling channels of the beam pipes, respectively. During the activation, the beam pipes were usually evacuated only by sputter ion pumps [6]. No problems were reported in these processes. $d P / d I$ decreases in a stepwise pattern after the NEG activation in each ring, as shown in Figs. 3 and 4. Note that the NEG pumps for the HER were sometimes activated only in the regions of the ring in which new beam pipes had been installed, since $d P / d I$ was already sufficiently low in the arc sections, as described in Sec. II B. Since the NEG 

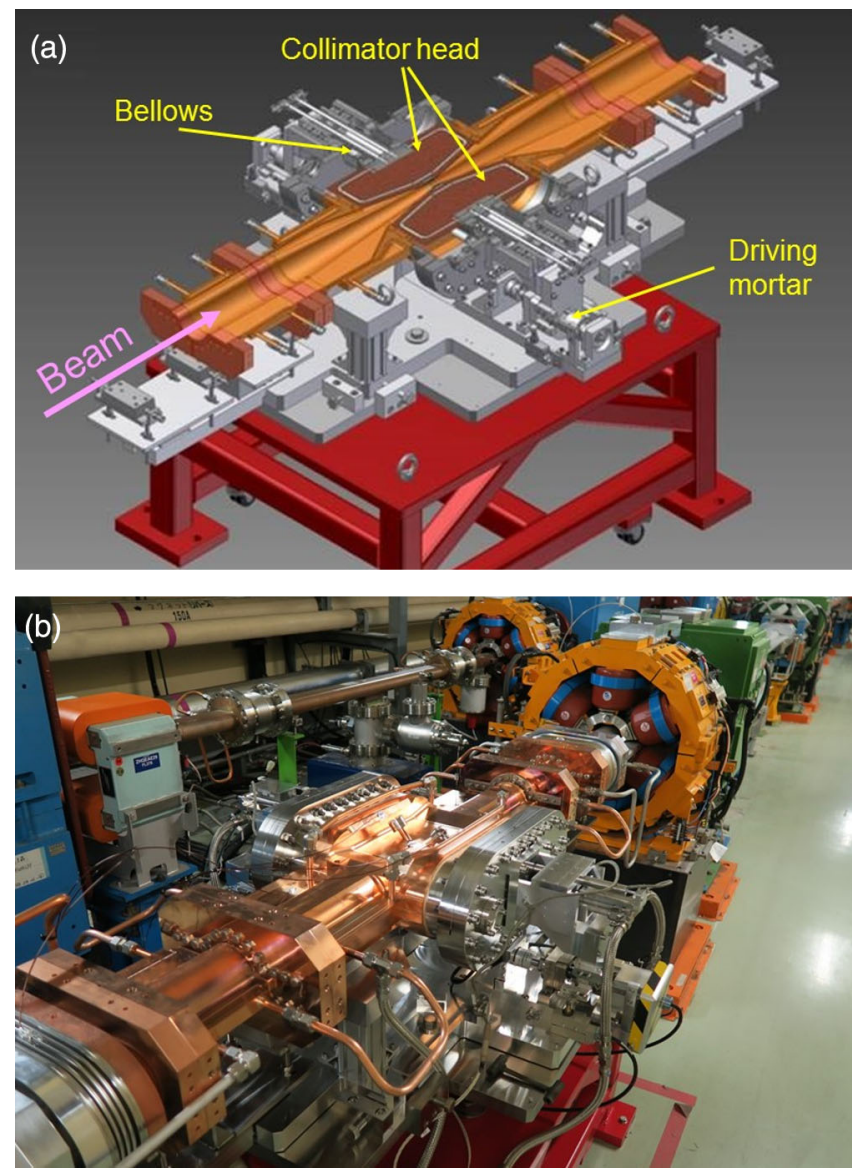

FIG. 7. (a) Conceptual structure and (b) test model of the new beam collimator installed in the LER arc sections.

pumps for the LER were installed in an antechamber along the beam pipes, it is necessary to switch off the currents of the quadrupole, sextupole and bending magnets to avoid oscillation of the heaters and NEG strips due to the ac current of the heaters. The change of the heater current from ac to dc is planned before the next commissioning.

Two beam collimators, which cut off the beam halo at the arc sections and then reduce the background noise of the particle detector, were installed in the LER for testing. The conceptual structure and first test model installed in the tunnel are presented in Figs. 7(a) and 7(b), respectively. These collimators were newly designed for SuperKEKB based on those used in PEP II at SLAC with the objective of minimizing the impedance $[42,43]$. The operability, heating, and collimator head positioning accuracy were checked using high beam currents. The collimator head position was remotely controlled successfully. The temperatures of the bellows behind the moving collimator head, where the excited HOM easily leaks through the coaxial waveguide structure, were several degrees at $1 \mathrm{~A}$. The effectiveness of the background noise reduction was also confirmed by a preliminary detector installed near the collision point [1]. Mass production will start soon in preparation for the next beam commissioning.
The vacuum chambers for the beam-size monitors using the SR or $\mathrm{x}$ rays emitted by the circulating beams were also newly fabricated to accommodate the new beam pipes with antechambers [44,45]. A beam-size monitor using SR consists of a vacuum chamber with a mirror located in an antechamber. To guide the $\mathrm{x}$ rays emitted by the circulating beams to the $\mathrm{x}$-ray line for the beam-size monitor, a special vacuum chamber was fabricated, a crotch absorber of which is installed in an antechamber. These structures contribute to the decrease of beam impedance since the mirror or crotch absorber is placed in an antechamber. No serious heating was observed in these vacuum chambers, and these beamsize monitors were useful for investigating the properties of stored beams.

Most of the hardware controlling the various vacuum components in the MR was reused, but the old components, such as the computer automated measurement and control system, were replaced with new ones [5]. All the vacuum components are monitored and controlled through a graphical user interface based on Control System Studio. The status of various components such as the vacuum pressures along the ring and the temperatures of the components can be checked at a glance. Although unexpected input-output controller shutdowns were occasionally observed in particular subcontrol rooms, the control system functioned properly during the Phase- 1 commissioning. The interlock and beam-abort logic based on a ladder-sequence program also worked well and contributed to the steady operation of the machine.

\section{Effects of ECE countermeasures}

The ECE is a key issue in the LER of SuperKEKB [14-18]. Various ECE countermeasures were prepared based on studies in numerous laboratories, such as CERN [46,47], Cornell University [48,49], and SLAC [50,51]. The countermeasures listed in Sec. I of this paper were also recommended for the positron damping ring of the International Linear Collider [52]. Thus, the countermeasure results obtained using SuperKEKB are applicable to future colliders as well.

The numbers of electrons around the circulating positron beam in a new Al-alloy beam pipe with antechambers were measured with the same electron current monitors that were used in previous KEKB experiments [53]. These electron monitors and the test beam pipe are shown in Fig. 8. The electron monitors were set at the bottom of the beam channel. The voltage applied to the electron collector was $100 \mathrm{~V}$, while that applied to the grid (repeller), which functions as an energy filter, was varied from 0 to $-500 \mathrm{~V}$. Two electron monitors were attached to the same beam pipe, as shown in Fig. 8: one in the region with TiN coating ([Al_Ante + TiN] in Fig. 8), which is also present in the other typical beam pipes in the ring, and one in the region without TiN coating ([Al_Ante] in Fig. 8). In other words, the electron currents at the locations with and without TiN 


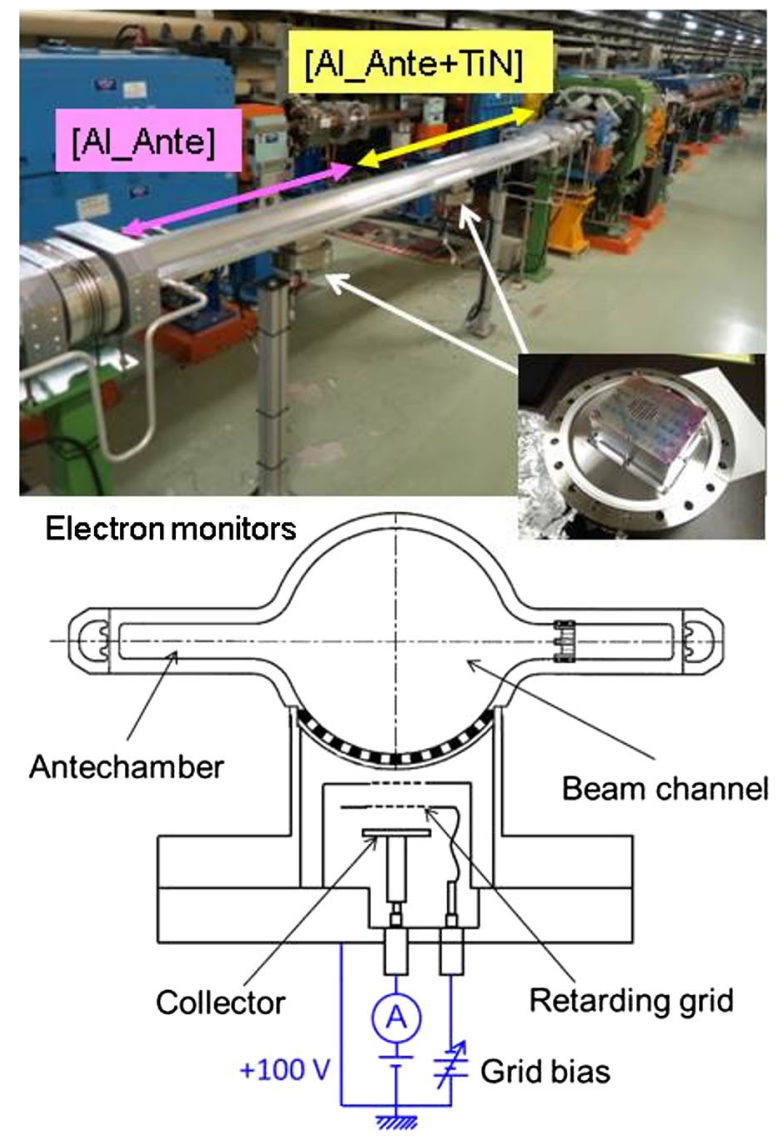

FIG. 8. Electron monitors attached to a test chamber with antechambers in an arc section of the LER. Here, [Al_Ante] and $\left[\mathrm{Al} \_\right.$Ante $\left.+\mathrm{TiN}\right]$ denote the Al region without and with TiN coating, respectively.

coating were measured simultaneously under the same beam conditions.

Figure 9 presents typical electron currents measured for the bunch fill pattern of $1 / 1576 / 6 n$. The measured electron currents approximately reflect the electron density around the beam path. The plots in Fig. 9 include the electron currents obtained in the KEKB experiments for a circular $\mathrm{Cu}$ beam pipe without ([Cu_Cir]) and with $\left(\left[\mathrm{Cu} \_\mathrm{Cir}+\mathrm{TiN}\right]\right)$ TiN coating for almost the same bunch fill pattern, 1/1500/6n. The electron currents are plotted as functions of the stored beam current. The numbers in parentheses represent the photon densities (photons s $\mathrm{s}^{-1} \mathrm{~m}^{-1}$ ) at the measurement points. The voltages applied to the grid and the electron collector were -30 and $+100 \mathrm{~V}$, respectively.

When the beam current is low $(<0.4 \mathrm{~A})$, the electrons in the beam pipe are mainly photoelectrons emitted by SR. Since the acceleration of the electrons by positron bunches is low, few secondary electrons are emitted from the inner surface of the pipe. As indicated by Fig. 9, the electron currents in the beam pipes with antechambers ([Al_Ante] and [Al_Ante $+\mathrm{TiN}]$ ), regardless of the presence or

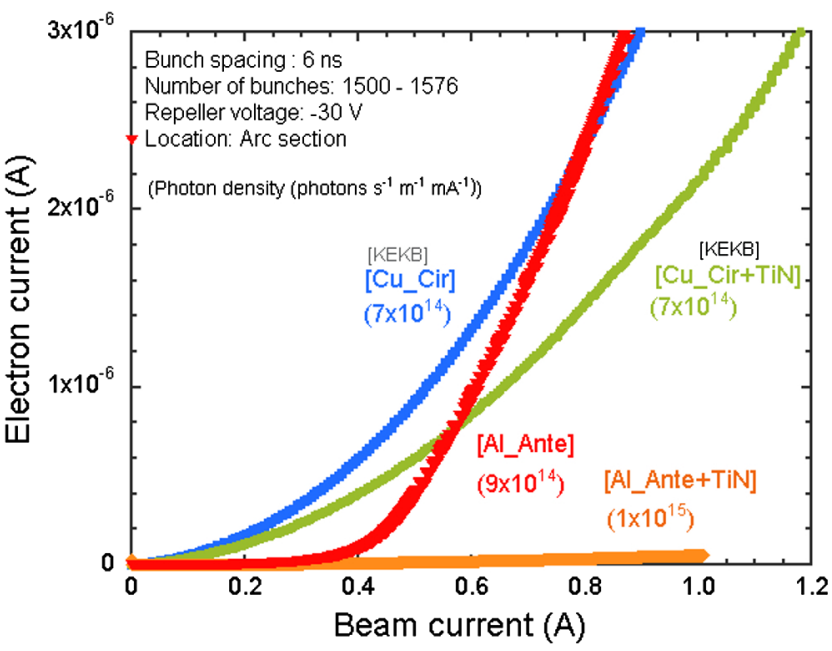

FIG. 9. Measured electron currents for four types of beam pipes for bunch fill patterns consisting of one train of 1500-1576 bunches with 6 ns bunch spacing. Here, [Cu_Cir + TiN] and [Cu_Cir] present the data obtained from $\mathrm{Cu}$ beam pipes having circular cross sections with and without TiN coating, respectively, which were measured in KEKB. [Al_Ante + TiN] and [Al_Ante] denote the data from Al-alloy beam pipes having antechambers with and without TiN coating, respectively. Note that the integrated beam doses achieved when the data of $\left[\mathrm{Cu}_{-} \mathrm{Cir}+\mathrm{TiN}\right]$, [Cu_Cir], [Al_Ante + TiN] and [Al_Ante] were measured were approximately 3200, 3900, 760, and $760 \mathrm{Ah}$, respectively.

absence of TiN coating, are smaller than those in the pipes without antechambers that were used in $\mathrm{KEKB}\left(\left[\mathrm{Cu} \_\mathrm{Cir}\right]\right.$ and $\left.\left[\mathrm{Cu}_{-} \mathrm{Cir}+\mathrm{TiN}\right]\right)$. The results clearly indicate the effectiveness of the antechambers in suppressing the photoelectrons in the beam channel.

When the beam current is high ( $>0.6 \mathrm{~A})$, the contribution of the secondary electrons should increase the electron cloud formation in the beam pipe. Figure 9 shows that the electron current in the Al-alloy beam pipe without TiN coating ([Al_Ante]) increases rapidly with increasing beam current. On the other hand, the electron current in the Alalloy beam pipe with TiN coating ([Al_Ante + TiN]) remains low. This result indicates that the TiN coating on the $\mathrm{Al}$ surface effectively reduces the SEY of the surface. Furthermore, the electron current in the Al-alloy beam pipe without TiN coating ([Al_Ante]) exceeds those in the $\mathrm{Cu}$ beam pipes ([Cu_Cir] and $\left.\left[\mathrm{Cu} \_\mathrm{Cir}+\mathrm{TiN}\right]\right)$. Thus, the SEY of a bare $\mathrm{Al}$ surface is higher than that of a bare or TiNcoated $\mathrm{Cu}$ surface. In fact, the SEYs of the TiN-coated surfaces are almost the same regardless of whether the substrate is $\mathrm{Cu}$ or $\mathrm{Al}$ alloy [5]. The difference between the electron currents in the TiN-coated $\mathrm{Cu}$ beam pipe without antechambers $\left(\mathrm{Cu}_{-} \mathrm{Cir}+\mathrm{TiN}\right)$ and the TiN-coated $\mathrm{Al}$ beam pipe with antechambers (Al_Ante $+\mathrm{TiN}$ ) should be due to the existence of antechambers, as well as the difference between the photon densities at the measurement points. The photoelectrons are still seeds of electron clouds in the 
beam pipe, even if the secondary electrons are the main cause of electron cloud formation when the beam current is high.

The clearing electrodes were prepared in wiggler magnets in two wiggler sections of the LER. In total, 116 clearing electrodes each $1.6 \mathrm{~m}$ long were installed. The clearing electrodes attract the electrons in the beam pipe by creating an electrostatic field [54]. During the Phase-1 commissioning, the maximum voltage of $+500 \mathrm{~V}$ was continuously applied at the maximum beam current of approximately $1 \mathrm{~A}$. No discharge, abnormal pressure rises, or overheating of the connectors was observed during the commissioning. The electron current flowing into the electrodes is a measure of the numbers of electrons in the beam pipes. The measured electron current increased almost linearly with increasing beam current when the applied voltage was constant. No difference was observed between the pressures near the electrodes that were measured when the applied voltage was 0 and $500 \mathrm{~V}$. These findings indicate that electron multipacting did not occur in the beam pipe. On the other hand, when the beam current is constant, the measured electron current increased with the applied voltage, but became saturated when the applied voltage reached approximately $100 \mathrm{~V}$. This result demonstrates that the electrodes absorbed the electrons in the beam pipe when the applied voltage was greater than $100 \mathrm{~V}$. However, the measured electron currents were lower than those expected based on the results of previous research and development at KEKB [31]. The electron density in the wiggler magnets during the Phase-1 commissioning might still have been low, and further observations and investigations at higher beam currents will be required in the future.

The effectiveness of grooves was not investigated during the Phase- 1 commissioning. We plan to install another test beam pipe with grooves in an arc section. The electron density in this beam pipe will be measured during the next commissioning.

No axial magnetic fields generated by solenoids or permanent magnets were applied to the beam pipes during the Phase- 1 commissioning. However, the axial magnetic fields in the Al-alloy bellows chambers were found to suppress the ECE very effectively, as described in Sec. III A.

\section{MAJOR PROBLEMS}

\section{A. Electron cloud effect}

A nonlinear pressure rise with increasing beam current was observed when the beam current was greater than $0.6 \mathrm{~A}$ throughout the LER and the usual bunch fill pattern, $1 / 1576 / 6 n$ was used. The typical behavior of the average pressure in an arc section is presented in Fig. 10(a) (without permanent magnets) and is similar to that shown in Fig. 9 ([Al_Ante]) for the electron current in the bare Al beam
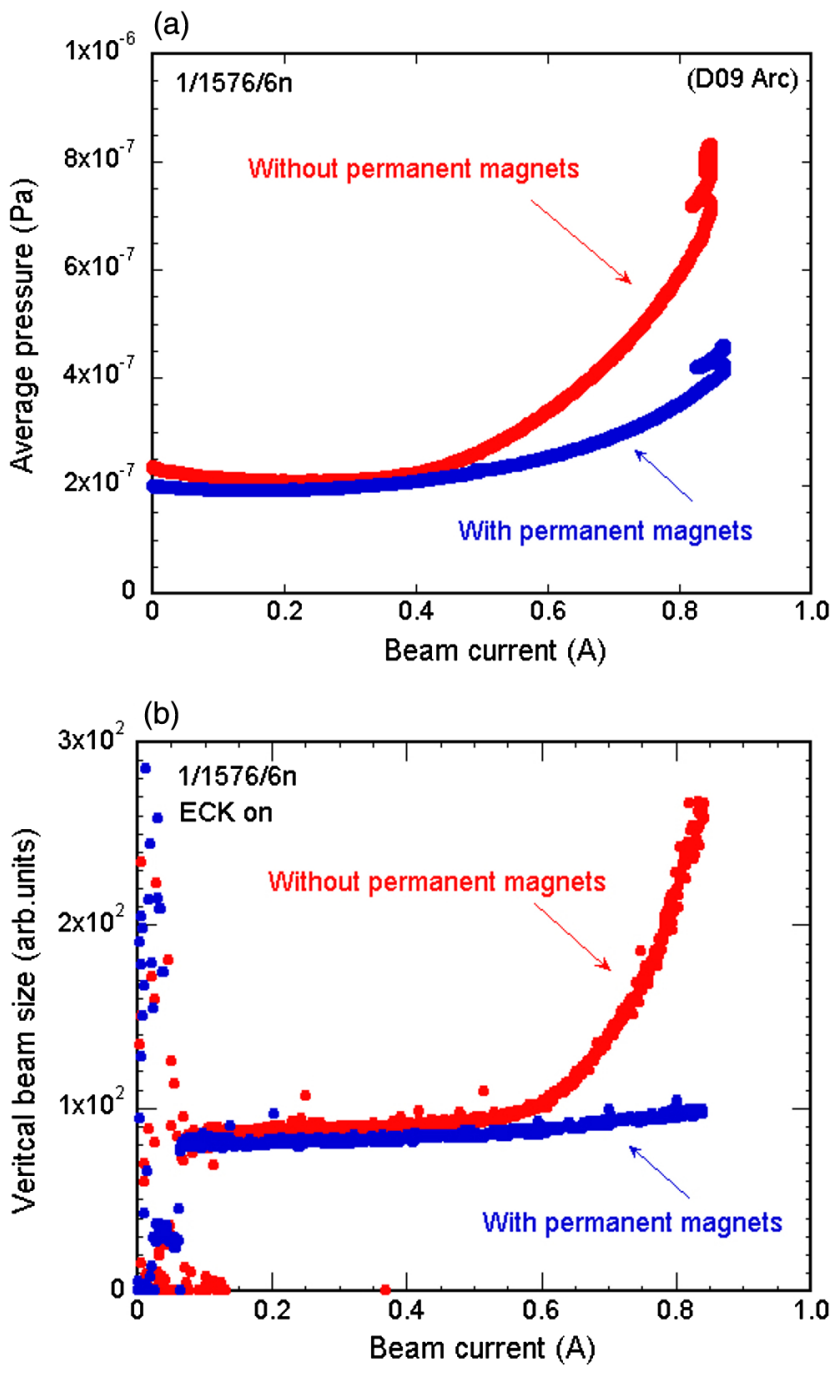

FIG. 10. Behaviors of (a) average pressure in an arc section and (b) vertical beam size versus beam current without and with permanent magnets on Al-alloy bellows chambers for the $1 / 1576 / 6$ n bunch fill pattern.

pipe region. It was suspected that the pressure rise was due to electron multipacting somewhere in the ring, that is, electron-stimulated desorption [55]. Furthermore, the beam begins to blow up vertically at almost the same beam current at which the nonlinear pressure increase begins as shown in Fig. 10(b) (without permanent magnets). Note here that the ECK is active in this case, but the behavior of the vertical beam size when the beam current is greater than 0.6 A does not depend on whether the ECK is switched on or off. It was also found in a machine study that the threshold beam current at which blowup began to develop depended on the bunch fill pattern. That is, the threshold current was lower for bunch fill patterns with shorter bunch spacing, and vice versa. In other words, the vertical beam size blowup started from almost the same bunch-charge density (i.e., bunch current divided by bunch spacing) irrespective of the bunch fill pattern [56]. These phenomena 
indicate ECE excitation in the ring. However, the electron density in the TiN-coated beam pipe ([Al_Ante + TiN] in Fig. 9) was still low at these beam currents. One possibility is that the ECE was excited by the electron clouds in the Al-alloy bellows chambers, which had no TiN coating. The Al-alloy bellows chambers are $200 \mathrm{~mm}$ long and are located every $3 \mathrm{~m}$ on average around the ring, as shown in Fig. 11(a). There are $\sim 830$ bellows chambers in total, and their combined length is $\sim 5 \%$ of the total length of the LER $(\sim 3 \mathrm{~km})$. Therefore, if the electron density in the A 1-alloy bellows chambers is 20 times that in the other regions, the ECE is likely to be excited in this ring. In fact, the electron current measured in the Al-alloy beam pipe without TiN coating ([Al_Ante]) is 50 times larger than that of the pipe with TiN coating ([Al_Ante + TiN]) at a beam current of $0.8 \mathrm{~A}$, as shown in Fig. 9.

To counteract the ECE, permanent magnets attached to $\mathrm{C}$-shaped iron plates (yokes) were placed at the top and bottom of each Al-alloy bellows chamber, as shown in Fig. 11(b). The axial (z-direction) and vertical (y-direction) magnetic fields measured at the top of the beam channel
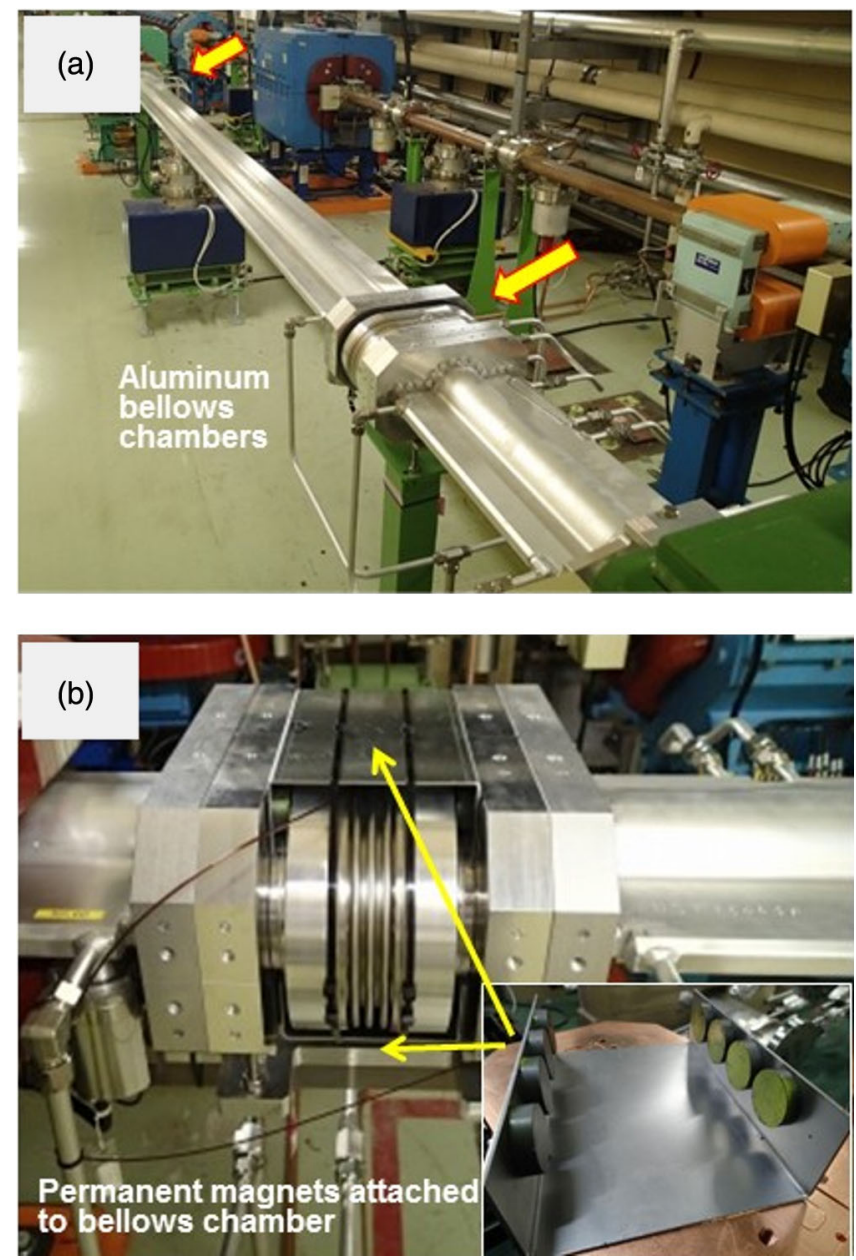

FIG. 11. (a) Al-alloy bellows chambers in the LER and (b) permanent magnets and yokes attached to the chambers. (point $\mathrm{U}$ in the figure) in a yoke are presented in Fig. 12 together with a schematic structure of a yoke. An axial magnetic field of approximately $100 \mathrm{G}$ is evident in most regions, although the polarity reverses near the magnets. After application of the permanent magnets, the nonlinear pressure rise relaxes substantially, as shown in Fig. 10(a) (with permanent magnets), and vertical beam size blowup is not evident until the beam current reaches approximately 0.8 A, as shown in Fig. 10(b) (with permanent magnets). Thus, the ECE was successfully suppressed by applying an axial magnetic field using permanent magnets on the Albellows chambers.

However, as the beam current increases further to approximately $1 \mathrm{~A}$, vertical beam size blowup appears again for the same bunch fill pattern $(1 / 1576 / 6 n)$. The nonlinear pressure rise with increasing beam current also becomes prominent at beam currents between 0.8 and $1 \mathrm{~A}$. It seems that the ECE was again excited in a part of the ring, possibly in the drift space where the Al-beam pipes with TiN coating were used. In fact, the electron density in the Al-alloy beam pipe with TiN coating ([Al_Ante + TiN] in Fig. 9) approaches the threshold density predicted by a simulation, which is approximately $2 \times 10^{11}{\text { electrons } \mathrm{m}^{-3}}^{-3}$ [57]. These characteristics must be investigated further during the next commissioning. Although vertical beam size blowup is not observable up to $1 \mathrm{~A}$ for a $1 / 1600 / 8 \mathrm{n}$ bunch fill pattern, which has a low bunch-charge density, the ECE could still be problematic in the next commissioning, in which beam currents greater than $1 \mathrm{~A}$ are expected.
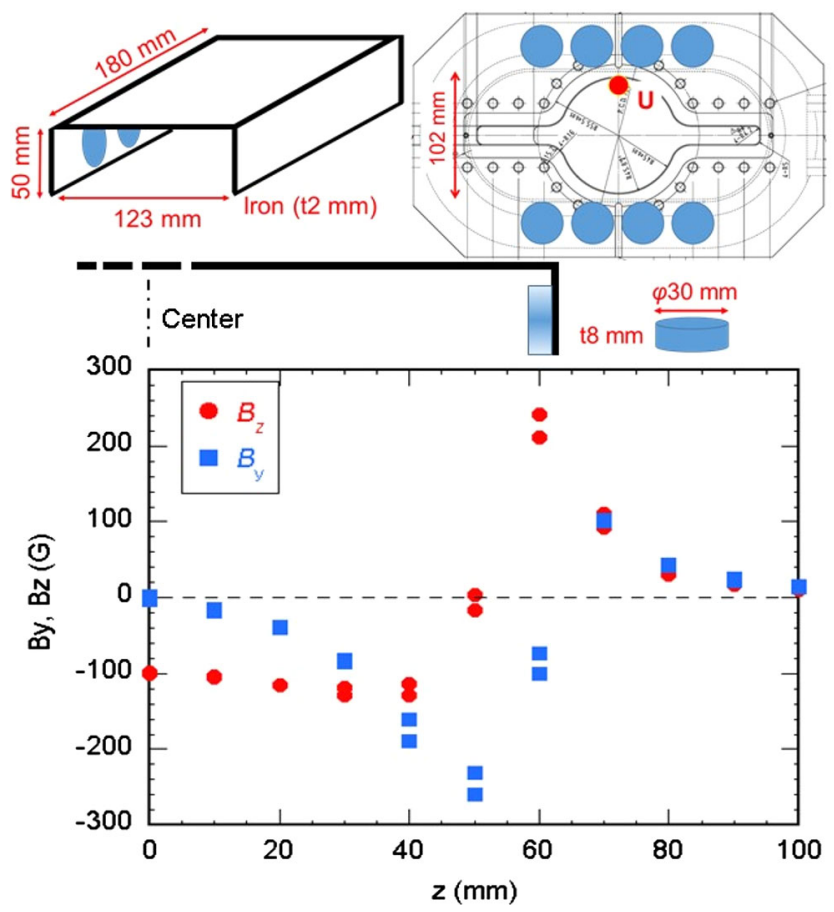

FIG. 12. Measured vertical (y) and axial (z) magnetic fields inside a yoke on the upper inner wall of the beam channel (point $\mathrm{U}$ in the drawing). 


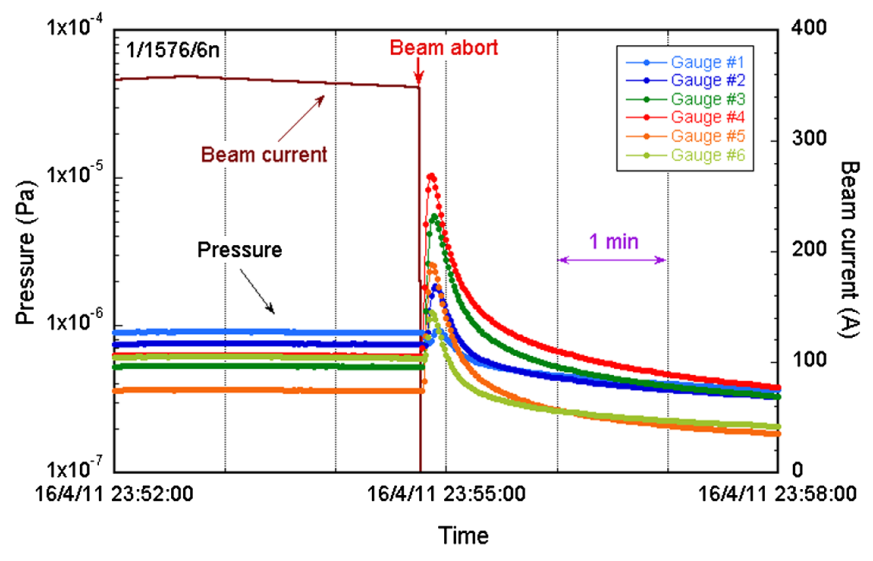

FIG. 13. Typical example of a pressure burst accompanying beam loss, followed by beam abortion.

It should be noted here that the threshold beam current necessary to excite ECE (that is, in concrete terms, the beam current at which the vertical beam size blowup begins) is much higher for SuperKEKB than for KEKB [56]. For example, the threshold bunch-charge density is approximately $0.1 \mathrm{mAns}^{-1}(\sim 1000 / 1576 / 6)$ for SuperKEKB (after applying permanents magnets to only the Al-alloy bellows chambers) and $0.02 \mathrm{mAns}^{-1}(\sim 60 / 4 / 60 / 6)$ for KEKB (without solenoids). In fact, in Fig. 9, the electron current of the Al-alloy beam pipe with TiN coating ([Al_Ante $+\mathrm{TiN}]$ ) at approximately $1 \mathrm{~A}$ is close to that of the $\mathrm{Cu}$ beam pipe without TiN coating ([Cu_Cir]) at approximately $0.2 \mathrm{~A}$. This similarity indicates that the antechambers and TiN coating of the beam pipes effectively suppress the ECE, as was already indicated by the electron current measurements presented in the previous section.

\section{B. Pressure bursts accompanying beam loss}

Another major concern during the Phase-1 commissioning was the localized pressure burst phenomenon accompanying beam loss in the LER. The beam loss monitors triggered beam aborts, and sometimes the pressure bursts became obstacles during the beam commissioning. A typical pressure burst is shown in Fig. 13. Pressure bursts were detected by several vacuum gauges, and the position of each burst could be deduced based on the pressure distribution along the ring. These bursts were frequently observed, starting from the early stage of the commissioning [38]. Pressure bursts were eventually observed at more than 10 points around the ring but were observed the most frequently in particular beam pipes. Specially, most of the pressure bursts occurred near or inside Al-alloy beam pipes in dipole magnets. Furthermore, the beam current at which the bursts occurred increased gradually with increasing maximum stored beam current $\left(I_{\max }\right)$. Figure 14 shows the numbers of bursts occurring per $50 \mathrm{~h}$ of operation time (red bars), the beam currents when the pressure bursts occurred (blue circles), and $I_{\max }$ (black lines) versus the duration of

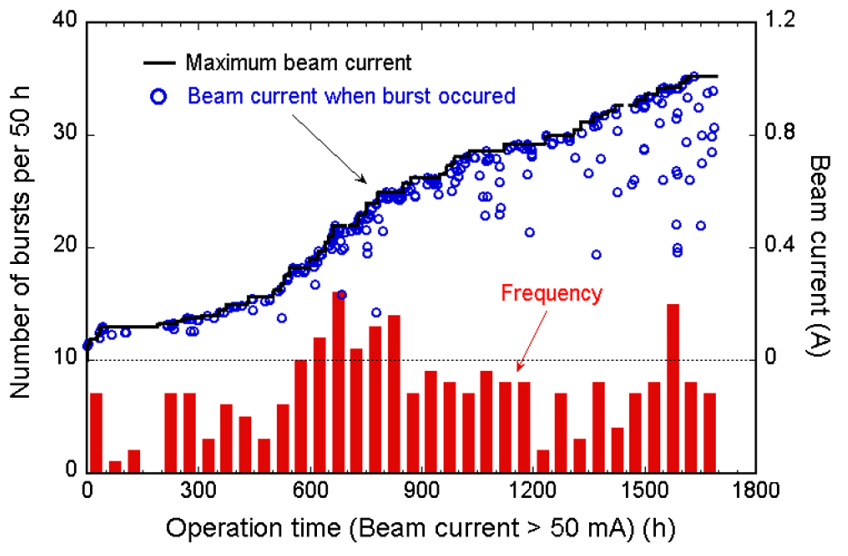

FIG. 14. Number of pressure bursts per $50 \mathrm{~h}$ (red bars), beam current when each burst occurred (blue circles), and maximum beam current (black line) as functions of the duration of operation with a beam current greater than $50 \mathrm{~mA}$.

operation with a beam current greater than $50 \mathrm{~mA}$. The frequency increases with increasing $I_{\max }$, while it tends to decrease when $I_{\max }$ remains almost constant.

The causes of the pressure bursts are not yet well understood, although the most probable cause is collisions between the circulating beams and dusts (small particles) in the beam pipes. In fact, in the beam pipes, we found small dust particles composed of $\mathrm{Al}_{2} \mathrm{O}_{3}$, carbon oxide (i.e., plastic or fibers), $\mathrm{Si}$ (i.e., some polishing material), $\mathrm{V}$ and $\mathrm{Ti}$ (NEG ingredients), and so on and had a typical size of $50 \mu \mathrm{m}$. Furthermore, the longitudinal grooves in the beam pipes in the dipole magnets, which counteract the ECE, are likely to trap dust during the manufacturing process. It is also difficult to clean the dust particles out from the bottoms of the grooves. As further evidence, the pressure bursts and simultaneous beam loss at a beam current of approximately 0.8 A were reproduced during a test using a knocker attached to several beam pipes in the dipole magnets. A similar phenomenon was reportedly observed in the LHC $[58,59]$. Careful investigation and continuous observation will be required in the next run.

\section{CONCLUSION}

The SuperKEKB vacuum system functioned correctly during the Phase-1 commissioning. Vacuum scrubbing progressed steadily as expected. No abnormal temperature increases or discharges were observed in the new vacuum components up to a beam current of approximately $1 \mathrm{~A}$. The beam collimator test model also worked well. The effectiveness of the antechambers and TiN coating of the beam pipes in counteracting the ECE in the LER was confirmed. However, a nonlinear pressure increase due to the ECE, which was caused by the electron clouds in the Al-alloy bellows chambers without TiN coating, was observed. The use of permanent magnets forming axial magnetic fields eliminated the ECE up to a beam current of 
0.9 A when the usual bunch fill pattern was used. However, the ECE began to appear around $1 \mathrm{~A}$ for the same bunch fill pattern. The pressure bursts accompanying beam aborts were also problematic in the LER; these are most likely caused by collisions between the circulating beam and dust particles in the beam pipe, but further investigation is required.

The Phase- 2 commissioning, which will be performed using a new particle detector, is planned to start next year. A stored current of more than $1 \mathrm{~A}$ is expected in this phase. During the long shutdown time before the Phase- 2 commissioning begins, new vacuum components for the particle detector will be installed in the ring, and the additional beam collimators will be installed to suppress the background noise of the detector. The construction of a damping ring for positron beams is ongoing. Furthermore, some countermeasures against the ECE that occurs at high currents, such as permanent magnets in drift regions, will be prepared in the LER. Potential countermeasures against the pressure bursts are now under consideration. Finally, some components that exhibited overheating and air leaks during the Phase-1 commissioning will be checked and replaced if necessary.

\section{ACKNOWLEDGMENTS}

We thank all the KEKB accelerator division staff for their cooperation and continuous encouragement during the construction phase and the Phase- 1 commissioning.

[1] Y. Funakoshi et al., Beam commissioning of SuperKEKB, in Proceedings of the International Particle Accelerator Conference, Busan, Korea, 2016 (JACoW, CERN, Geneva, 2016), pp. 1019-1021.

[2] T. Miura et al., Progress of SuperKEKB, in Proceedings of the International Particle Accelerator Conference, Richmond, VA, 2015 (JACoW, CERN, Geneva, 2015), pp. 1291-1295.

[3] Y. Ohnishi et al., Accelerator design at SuperKEKB, Prog. Theor. Exp. Phys. (2013) 03A011.

[4] T. Abe et al., Achievements of KEKB, Prog. Theor. Exp. Phys. (2013) 03A001.

[5] Y. Suetsugu, K. Kanazawa, K. Shibata, T. Ishibashi, H. Hisamatsu, M. Shirai, and S. Terui, Results and problems in the construction phase of the SuperKEKB vacuum system, J. Vac. Sci. Technol. A 34, 021605 (2016).

[6] Y. Suetsugu, K. Kanazawa, K. Shibata, T. Ishibashi, H. Hisamatsu, M. Shirai, and S. Terui, Construction status of the SuperKEKB vacuum system, Vacuum 121, 238 (2015).

[7] K. Kanazawa, Y. Suetsugu, S. Kato, K. Shibata, T. Ishibashi, H. Hisamatsu, M. Shirai, M. Shimamoto, M. Satoh, M. Nishiwaki, and S. Terui, Experiences at the KEK B-factory vacuum system, Prog. Theor. Exp. Phys. (2013) $03 \mathrm{~A} 005$
[8] Y. Suetsugu, K. Kanazawa, S. Kato, H. Hisamatsu, M. Shimamoto, and M. Shirai, Present status of the KEKB vacuum system, J. Vac. Sci. Technol. A 21, 1436 (2003).

[9] T. Abe, T. Ishibashi, Y. Morita, K. Ohmi, K. Shibata, Y. Suetsugu, M. Tobiyama, and D. Zhou, Impedance calculation and simulation of microwave instability for the main rings of SuperKEKB, in Proceedings of the International Particle Accelerator Conference, Dresden, Germany, 2014 (JACoW, CERN, Geneva, 2014), pp. 1600-1602.

[10] Y. Suetsugu, K. Shibata, H. Hisamatsu, M. Shirai, and K. Kanazawa, Development of copper beam ducts with antechambers for advanced high-current particle storage rings, Vacuum 84, 694 (2009).

[11] Y. Suetsugu et al., R\&D of copper beam duct with antechamber scheme for high current accelerators, Nucl. Instrum. Methods Phys. Res., Sect. A 538, 206 (2005).

[12] J. A. Crittenden, D. C. Sagan, T. Ishibashi, and Y. Suetsugu, Synchrotron radiation analysis of the SuperKEKB positron ring, in Proceedings of the International Particle Accelerator Conference, Richmond, VA, 2015 (JACoW, CERN, Geneva, 2015), pp. 2222-2224.

[13] D. Hunt, K. Kennedy, and T. Stevens, Design of the PEP-II low energy ring vacuum system, in Proceedings of the Particle Accelerator Conference and International Conference on High-Energy Accelerators, Dallas, TX, 1995 (IEEE, Piscataway, NJ, 1996), pp. 2067-2068.

[14] K. Ohmi, Beam-photoelectron interactions in positron storage rings, Phys. Rev. Lett. 75, 1526 (1995).

[15] M. Izawa, Y. Sato, and T. Toyomasu, The vertical instability in a positron bunched beam, Phys. Rev. Lett. 74, 5044 (1995).

[16] K. Ohmi and F. Zimmermann, Head-tail instability caused by electron clouds in positron storage rings, Phys. Rev. Lett. 85, 3821 (2000).

[17] F. Zimmermann, CERN Report No. CERN-SL-Note-2000004 AP, 2000.

[18] F. Zimmermann, Review of single-bunch instabilities driven by an electron cloud, Phys. Rev. ST Accel. Beams 7, 124801 (2004).

[19] Y. Suetsugu, K. Kanazawa, K. Shibata, M. Shirai, A. E. Bondar, V. S. Kuzminykh, A. I. Gorbovsky, K. Sonderegger, M. Morii, and K. Kawada, Development of bellows and gate valves with a comb-type rf-shield for high-current accelerators: Four years' beam test at KEK B-Factory, Rev. Sci. Instrum. 78, 043302 (2007).

[20] Y. Suetsugu, M. Shirai, and K. Shibata, Possibility of comb-type rf shield structure for high-current accelerators, Phys. Rev. ST Accel. Beams 6, 103201 (2003).

[21] Y. Suetsugu, M. Shirai, and M. Ohtsuka, Application of stain-less steel, copper alloy and aluminum alloy MO (Matsumoto-Ohtsuka) -type flanges to accelerator beam pipes, in Proceedings of the International Particle Accelerator Conference, Kyoto, Japan (ICR, Kyoto, 2010), pp. 3855-3857.

[22] Y. Suetsugu, M. Shirai, and M. Ohtsuka, Application of MO-type vacuum flange to beam duct for highcurrent accelerators, J. Vac. Sci. Technol. A 23, 1721 (2005).

[23] Y. Suetsugu, K. Shibata, and M. Shirai, Design study of distributed pumping system using multilayer NEG strips 
for particle accelerators, Nucl. Instrum. Methods Phys. Res., Sect. A 597, 153 (2008).

[24] Y. Suetsugu, K. Kanazawa, K. Shibata, T. Ishibashi, H. Hisamatsu, M. Shirai, and S. Terui, Design and construction of the SuperKEKB vacuum system, J. Vac. Sci. Technol. A 30, 031602 (2012).

[25] Y. Suetsugu, K. Kanazawa, K. Shibata, and H. Hisamatsu, Continuing study on the photoelectron and secondary electron yield of TiN coating and NEG (Ti-Zr-V) coating under intense photon irradiation at the KEKB positron ring, Nucl. Instrum. Methods Phys. Res., Sect. A 556, 399 (2006).

[26] K. Kennedy, B. Harteneck, G. Millos, M. Benap, F. King, and R. Kirby, TiN coating of the PEP-II low-energy ring aluminum arc vacuum chambers, in Proceedings of the Particle Accelerator Conference, Vancouver, BC, Canada, 1997 (IEEE, New York, 1997), pp. 3568-3570.

[27] K. Shibata, H. Hisamatsu, K. Kanazawa, M. Shirai, and Y. Suetsugu, Development of TiN coating system for beam ducts of KEK B-factory, in Proceedings of the 11th European Particle Accelerator Conference, Genoa, 2008 (EPS-AG, Genoa, Italy, 2008), pp. 1700-1702.

[28] J. R. Calvey et al., Update on electron cloud mitigation studies at CesrTA, in Proceedings of the 2nd International Particle Accelerator Conference, San Sebastián, Spain (EPS-AG, Spain, 2011), pp. 796-798.

[29] J. R. Calvey, W. Hartung, Y. Li, J. A. Livezey, J. Makita, M. A. Palmer, and D. Rubin, Measurements of electron cloud growth and mitigation in dipole, quadrupole, and wiggler magnets, Nucl. Instrum. Methods Phys. Res., Sect. A 770, 141 (2015).

[30] D. Alesini, A. Drago, A. Gallo, S. Guiducci, C. Milardi, M. Zobov, S. De Santis, T. Demma, and P. Raimondi, Experimental measurements of e-cloud mitigation using clearing electrodes in the DAФNE collider, in Proceedings of the 3rd International Particle Accelerator Conference, New Orleans, LA, 2012 (IEEE, Piscataway, NJ, 2012), pp. 1107-1109.

[31] Y. Suetsugu, H. Fukuma, K. Shibata, M. Pivi, and L. Wang, Beam tests of a clearing electrode for electron cloud mitigation at KEKB positron ring, in Proceedings of the International Particle Accelerator Conference, Kyoto, Japan, 2010 (ICR, Kyoto, 2010), pp. 2369-2371.

[32] Y. Suetsugu, H. Fukuma, M. Pivi, and L. Wang, Continuing study on electron-cloud clearing techniques in highintensity positron ring: mitigation by using groove surface in vertical magnetic field, Nucl. Instrum. Methods Phys. Res., Sect. A 604, 449 (2009).

[33] Y. Suetsugu, H. Fukuma, K. Shibata, M. Pivi, and L. Wang, Experimental studies on grooved surfaces to suppress secondary electron emission, in Proceedings of the International Particle Accelerator Conference, Kyoto, Japan, 2010 (ICR, Kyoto, 2010), pp. 2021-2023.

[34] L. F. Wang, D. Raparia, J. Wei, and S. Y. Zhang, Mechanism of electron cloud clearing in the accumulator ring of the Spallation Neutron Source, Phys. Rev. ST Accel. Beams 7, 034401 (2004).

[35] Y. Cai, M. Pivi, and M. Furman, Buildup of electron cloud with different bunch pattern in the presence of solenoid field, in Proceedings of the Particle Accelerator
Conference, Portland, OR, 2003 (IEEE, New York, 2003), pp. 350-352.

[36] Y. Funakoshi et al., Recent Progress at KEKB, in Proceedings of the 10th European Particle Accelerator Conference, Edinburgh, Scotland, 2006 (EPS-AG, Edinburgh, Scotland, 2006), pp. 610-612.

[37] H. Fukuma, J. W. Flanagan, T. Kawamoto, T. Morimoto, K. Oide, M. Tobiyama, and F. Zimmermann, The effect of the solenoid field in quadrupole magnets on the electron cloud instability in the KEKB LER, in Proceedings of the 10th European Particle Accelerator Conference, Edinburgh, Scotland, 2006 (EPS-AG, Edinburgh, Scotland, 2006), pp. 2901-2902.

[38] Y. Suetsugu, H. Hisamatsu, T. Ishibashi, K. Kanazawa, K. Shibata, M. Shirai, and S. Terui, First Commissioning of the SuperKEKB Vacuum System, in Proceedings of the International Particle Accelerator Conference, Busan, Korea, 2016 (JACoW, CERN, Geneva, 2016), pp. 1086-1088.

[39] K. Shibata, H. Hisamatsu, K. Kanazawa, M. Shirai, and Y. Suetsugu, Gas desorption from TiN-coated copper beam duct, in Proceedings of the Particle Accelerator Conference, Vancouver, Canada, 2009 (TRIUMF, Canada, 2010), pp. 381-383.

[40] Y. Suetsugu, T. Kageyama, K. Shibata, and T. Sanami, Latest movable mask system for KEKB, Nucl. Instrum. Methods Phys. Res., Sect. A 513, 465 (2003).

[41] N. Biancacci et al., Impedance measurements and simulations on the TCT and TDI LHC collimators, in Proceedings of the International Particle Accelerator Conference, Busan, Korea, 2016 (JACoW, CERN, Geneva, 2016), pp. 610-613.

[42] T. Ishibashi, Y. Suetsugu, and S. Terui, Design of collimator for SuperKEKB positron ring, in Proceedings of the 10th Annual Meetings of Particle Accelerator Society of Japan, Nagoya, Japan (Particle Accelerator Society of Japan, Tokyo, Japan, 2013), pp. 1191-1195.

[43] S. DeBarger, S. Metcalfe, C. Ng, T. G. Porter, J. Seeman, M. Sullivan, and U. Wienands, SLAC Report No. SLACPUB-11752, 2001.

[44] J. W. Flanagan et al., Single-shot resolution of X-ray monitor using coded aperture imaging, in Proceedings of the 10th European Workshop on Beam Diagnostics and Instrumentation

for Particle Accelerators, Hamburg, Germany (DESY, Hamburg, 2011), pp. 561-563.

[45] J. P. Alexander et al., Low energy coded aperture performance at the CESR-TA X-ray beam size monitor, in Proceedings of the International Particle Accelerator Conference, Dresden, Germany, 2014 (JACoW, CERN, Geneva, 2014), pp. 3741-3743.

[46] V. Baglin, J. Bojko, O. Gröbner, B. Henrist, N. Hilleret, C. Scheuerlein, and M. Taborelli, The secondary electron yield of technical materials and its variation with surface treatments, in Proceedings of the European Particle Accelerator Conference, Vienna, Austria, 2000 (EPSAG, Vienna, Austria, 2008), pp. 217-219.

[47] B. Henrist, H. Hilleret, C. Scheuerlein, and M. Taborelli, The secondary electron yield of TiZr and TiZrV nonevaporable getter thin film coatings, Appl. Surf. Sci. 172, 95 (2001). 
[48] M. A. Palmer et al., The conversion and operation of the cornel electron storage ring as a test accelerator (CESRTA) for damping rings research and development, in Proceedings of the Particle Accelerator Conference, Vancouver, Canada, 2009 (TRIUMF, Canada, 2010), pp. 4200-4204.

[49] M. A. Palmer et al., Electron cloud at low emittance in CESRTA, in Proceedings of the International Particle Accelerator Conference, Kyoto, Japan, 2010 (ICR, Kyoto, 2010), pp. 1251-1255.

[50] R. E. Kirby and F. K. King, Secondary electron emission yields from PEP-II accelerator materials, Nucl. Instrum. Methods Phys. Res., Sect. A 469, 1 (2001).

[51] F. Le Pimpec, R. E. Kirby, F. King, and M. Pivi, TiN and TiZr-V thin film as a remedy against electron cloud, Nucl. Instrum. Methods Phys. Res., Sect. A 551, 187 (2005).

[52] M. T. F. Pivi et al., Recommendation for the feasibility of a $3 \mathrm{~km}$ Damping Ring, in Proceedings of the International Particle Accelerator Conference, Kyoto, Japan, 2010 (ICR, Kyoto, 2010), pp. 3578-3580.

[53] K. Kanazawa, H. Fukuma, H. Hisamatsu, and Y. Suetsugu, Measurement of the electron cloud density around the beam, in Proceedings of the 21st Particle Accelerator Conference, Knoxville, TN, 2005 (IEEE, Piscataway, NJ, 2005), pp. 1054-1056.
[54] L. Wang, H. Fukuma, S. Kurokawa, M. Pivi, and G. Xia, Perfect electrode to suppress secondary electrons inside the magnets, in Proceedings of the 10th European Particle Accelerator Conference, Edinburgh, Scotland, 2006 (EPSAG, Edinburgh, Scotland, 2006), pp. 1489-1491.

[55] I. R. Collins, O. Gröbner, P. Lepeule, and R. Veness, Mechanical and vacuum stability design criteria for the LHC experimental vacuum chambers, in Proceedings of the European Particle Accelerator Conference, Stockholm, Sweden, 1998 (Institute of Physics Publishing, London, 1998), pp. 2202-2204.

[56] H. Fukuma et al., Observation of vertical beam blow-up in KEKB low energy ring, in Proceedings of the European Particle Accelerator Conference, Vienna, Austria, 2000 (EPS-AG, Vienna, Austria, 2008), pp. 1122-1124.

[57] K. Ohmi and D. Zhou, Study of electron cloud effects in SuperKEKB, in Proceedings of the International Particle Accelerator Conference, Dresden, Germany, 2014 (JACoW, CERN, Geneva, 2014), pp. 1597-1599.

[58] G. Papotti, M. Albert, B. Auchmann, E. B. Holzer, M. Kalliokoski, and A. Lechner, Macroparticle-induced losses during 6.5 TeV LHC operation, in Proceedings of the International Particle Accelerator Conference, Busan, Korea, 2016 (JACoW, CERN, Geneva, 2016), pp. 1481-1484.

[59] T. Baer et al., Report No. CERN-THESIS-2013-233, 2013. 